\title{
Digital Service Innovation Enabled by Big Data Analytics - A Review and the Way Forward
}

\author{
Aya Rizk \\ Luleå University of Technology \\ aya.rizk@1tu.se
}

\author{
Birgitta Bergvall-Kåreborn \\ Luleå University of Technology \\ birgitta.bergvall- \\ kareborn@1tu.se
}

\author{
Ahmed Elragal \\ Luleå University of Technology \\ ahmed.elragal@1tu.se
}

\begin{abstract}
Service innovation is attracting attention with the expanding service industries and economies. Accompanied by major developments in ICT and sensory and digital technologies, the interest in digital service innovation (DSI), both from academia and industry, is increasing. Digitization and the accompanying technological advancements are leading to phenomena that call for extensive research in relation to service innovation; one of which is big data analytics (BDA). In this paper, we review the DSI literature and explore how BDA can contribute along the different dimensions of DSI. The ex post literature suffers from the lack of such studies. Accordingly, we suggest a research agenda for BDA-enabled DSI, motivated by emerging research gaps, as well as opportunities and guiding research questions. It is expected that such research agenda will contribute to shape an ex ante research efforts in an attempt to advance the state-of-the-art in BDA-enabled DSI.
\end{abstract}

\section{Introduction}

Digital Service Innovation (DSI) is an emerging research domain focusing on understanding the mechanisms by which digital technologies can enable innovation of service. There are two strong motivational forces behind the emergence of DSI. Firstly, the interest in service innovation among public and private organizations has grown considerably over the last decade [1] as they strive to strengthen their innovative capacity [6], giving way to concepts and paradigms such as product service systems [7], servitization [8], and service-dominant logic [9]. Secondly, the pervasiveness of digital technology in society at large has its impact on service innovation evident through diverse phenomena such as social media practices [2], Internet of things [3], and crowdsourcing $[4,5]$.
Common to most of the above-mentioned phenomena is that their enactment generates or is enabled by large amounts of digital traces, namely big data. For instance, a feature like Google Traffic would not have emerged if it were not for the crowdsourcing of traffic and mobile usage data, pervasiveness of mobile apps such as Google Maps and Big Data analytics (BDA) techniques that estimate traffic conditions in real-time. While BDA is often reported to bring high returns to organizations investing in its technologies [11-13], it is often overlooked in relation to service research and service innovation [10][14][43].

As seen in the example above, DSI and BDA are becoming increasingly intertwined, yet with minimum reflection in the literature. This paper seeks to breach this gap by conducting a literature review that explores the presence and potential of BDA in relation to DSI. The aim is to identify areas and approaches where BDA can create added value for service innovations. Based on the results of the study we put forward a research agenda aimed to further develop the DSI field by highlighting opportunities arising from the utilization of BDA.

Towards this end, we provide a brief overview of DSI and BDA, which together set our literature search boundaries. The methodology follows with a description of our literature search and analysis. Subsequently, the anatomy of DSI and its emergent research streams are described, including BDA contributions within these streams. Finally, a research agenda is provided, by highlighting the research gaps and guiding research questions, before we conclude.

\section{Service innovation in digital ecosystems}

Within the service innovation literature, three trends can be observed: 1) a shift in focus from a market-driven to a service-dominant (SD) mindset [9], where service is considered the basis of exchange rather than a variation of products [58], 2) the emergence and theorization of digital platforms and infrastructures that utilize third-party contributors to 
provide digital services $[81,82]$, and 3) an interest in digital platforms as sociotechnical phenomenon, including actors, connections between actors, the transactions along these connections and processes of use $[84,85]$, which link it to the concept of ecosystems.

Each of these trends represents an anchor for grounding DSI research, on which we expand our results in this paper. The focus on service as a unit of analysis and of exchange in research and practice, respectively, is key to DSI due to a) the transformative role of ICT in creating new opportunities for innovation in services [9], and b) the role of users as co-creators of value [15][21].

Alternatively, digital platforms and infrastructures can be found in various markets, but share common architectural principles based on reuse and modularity. This modular architecture symbolizes an ideal type of generativity through the "overall capability to produce unprompted change driven by large, varied and uncoordinated audiences" [73, p. 1980].

Moreover, while service innovation extends beyond traditional organizational boundaries into digital ecosystems, the sociotechnical perspective reveals interesting contemporary dynamics related to the DSI process, and that of service use [63]. Nevertheless, these trends overlap, as is evident through Eaton et al.'s [86] definition of service innovation: "a novel process of applying immaterial technology (operant resources) on material technology (operand resources) in order to create unforeseen value to other actors through new (re-) combinations of the two by leveraging the unique materiality of digital technology." [p. 5] For the purpose of this paper, we take this definition and the above-mentioned trends as our starting point to identify the relevant DSI literature.

\section{Big data analytics}

While the three trends presented above are well documented and clearly anchored to service innovation, this is not the case with BDA, albeit gaining attention during the recent years. Specifically in the IS field, special issues from the major journals have been dedicated to, or included articles on, big data $^{1}[22,23]$. This trend has materialized more in practice, where a "Data Scientist" has been one of the hottest jobs in the market for a few years now [12][24].

This highlight on big data and data science is linked to advancements in computing, sensors, networking and data storage technologies that enable the collection of data, often in real-time, to reach unprecedented peaks $[25,26]$. Even though some scholars argue that we always had a big data problem [27], it is relatively

\footnotetext{
${ }^{1}$ http://www.palgrave-journals.com/jit/journal/v30/n1/index.html
}

recently that academia and the industry are working on an explicit understanding for the phenomenon.

The literature on big data is filled with notions, characteristics and properties, but rarely definitions. One reason for this is that what we agree on to be 'big' data is continuously changing [11]. The most common characteristics of big data are the 3 Vs: huge volumes, high velocity, and variety of types and structures $[28,29]$. Recently, two additional Vs have been suggested: veracity and value residing in the data [30].

$\mathrm{Wu}$ et al. [31] describe big data through their HACE theorem: "... heterogeneous, autonomous sources with distributed and decentralized control, and seeks to explore complex and evolving relationships among data." [p. 98]. This definition is similar to the 3 Vs, but calls for equal attention to the complex relationships among data and evolutionary nature. Yet, both approaches are relevant when the problem is concerned with big data management.

However, shifting focus from big data management to $\mathrm{BDA}$, result in definitions where analytical processing becomes the central component of big data. One of the earliest definitions of BDA [33] highlights both the social and the technical properties of big data as an emerging phenomenon, while encompassing management and analytical challenges of big data. Their definition incorporates the technological aspects where development is sought to collect, store, process and manage big data, as well as the analytical aspects where value is generated through the extraction of patterns supporting economic and social gains. In this paper, we adopt this view of big data focusing on the use of analytical techniques in order to generate individual, economic or social value from big data.

\section{Research method}

To present an overview of the current literature on big data-enabled DSI, we conducted a literature review following [34]. With the challenge of searching within two recent, seemingly disjoint domains; we followed a 3 -stage process detailed in the following subsections.

\subsection{Literature search}

Identifying the relevant literature started with a pilot search in ProQuest database, in order to construct suitable search phrases. The literal phrase ('big data analytics') was used as a search query for the BDA subset of our literature, since it is an established and commonly used keyword in published articles. Literature within DSI, on the other hand, is not unified under a common (set of) keyword, and the broader term service innovation could be addressed from 
different facets. Thus the search query for DSI was constructed from the following phrases (service AND [innovation OR transformation OR improvement] AND [digital OR ICT]). Our pilot search was also confined within the subject areas of information systems, computer science, economics, engineering \& technology, business and innovation disciplines, as well as peer-reviewed journals and conference proceedings. Results were limited to publications in the English language, published as of December $31^{\text {st }} 2015$.

The search was then replicated on four other databases: Scopus, Web of Science, IEEE Xplore, and ACM; since they cover the top IS journals and conferences [35]. In addition, 3 big data journals were searched: Big Data Research, Big Data, and the Journal of Big Data, using the same DSI search query.

\subsection{Screening}

After discarding duplicates, a total of 462 papers were collected and ready to be screened (see Table 1). This phase took place in two stages: title and abstract screening and full-text screening. Screening was primarily informed and bounded by the provided definition of DSI [86] and the integrative view of BDA [33]. Accordingly, big data literature that focused on a particular technological framework, algorithm, or its optimization was omitted for its lack of social relevance. Similarly, literature on innovation theories that lacked an ICT, digital technology dimension or contribution to the IS field was excluded.

Table 1. Literature search results

\begin{tabular}{|l|l|l|}
\hline Search steps & BDA & DSI \\
\hline ProQuest & 78 & 16 \\
\hline IEEE Xplore & 166 & 11 \\
\hline Scopus & 283 & 72 \\
\hline ACM DL & 36 & 0 \\
\hline WoS & 93 & 40 \\
\hline Big data journals & 49 & -- \\
\hline Total (with duplicates) & 701 & 139 \\
\hline Total (without duplicates) & 396 & 66 \\
\hline Filtered by abstract & 69 & 41 \\
\hline Filtered by content & 30 & 18 \\
\hline Added by backward \& forward search & 10 & 17 \\
\hline Total & $\mathbf{4 0}$ & $\mathbf{3 5}$ \\
\hline
\end{tabular}

Collectively, 110 articles were selected based on the abstract, downloaded and read for screening based on content. Finally, 48 articles were read thoroughly and 27 articles were added by means of backward and forward search [36], yielding 75 articles to be analyzed. The final set of papers to review was found to be published between 2000 and 2015, with the majority published after 2012 (see Fig.1).

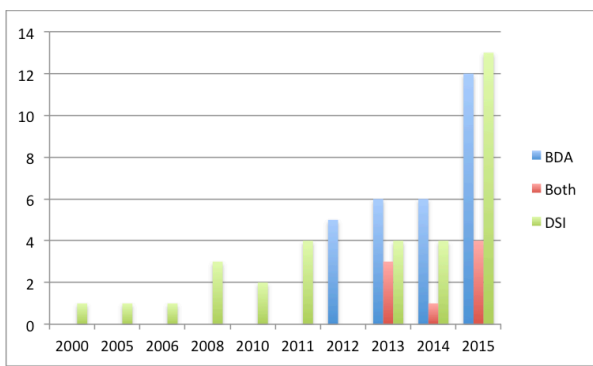

Figure 1: Publication frequency

\subsection{Synthesis \& analysis}

In order to understand the potential contribution or role of BDA in DSI, we sought to analyze and describe the anatomy of DSI literature first. As DSI represents an emerging phenomenon, conventional content analysis was found to be appropriate, as it avoids preconceived categories [37]. To that end, DSI papers were catalogued with tags on their reported problem definition, application domain, and unit of analysis. Clustering the literature along the former dimensions revealed no consistent pattern. The unit of analysis, however, revealed three main research streams that synthesize the domain of DSI: (1) digital service, (2) innovation process, and (3) digital infrastructures.

Using these three streams as a departure point for synthesizing BDA literature, the corresponding subset was analyzed in order to identify the existing and potential contributions of big data towards DSI. Existing research spanned the conceptual-empirical continuum, providing the body of knowledge with a wide range of research gaps and further opportunities. The research gaps found can be classified into the neglect-spotting mode of gap spotting identified by Sandberg and Alvesson [38]. They represent either overlooked, under researched areas, or studies that lack empirical support for their arguments or results. Further details are discussed in the following sections.

\section{DSI enabled by BDA}

Three dimensions emerged from the literature analysis, with DSI at the intersection thereof (see figure 2). The first dimension takes the service as a primary unit of analysis interpreted as a static artifact of innovation. The second dimension takes the innovation process as a unit of analysis including the stages and factors of the dynamic unfolding of service innovation. The third dimension takes infrastructure as a primary unit of analysis where enabling resources for DSI and their properties are discussed, as well as the surrounding ecosystem. For simplicity, we discuss these three dimensions in three subsections, even 
though some studies have more than a unit of analysis and/or handle issues surfacing at the intersection of two dimensions. For example, while business models can impact the service [55] as well as organizational innovation processes [69], we chose to discuss them under the latter dimension due to their dynamic nature.

\subsection{The service}

Service innovation has long taken the service as a primary unit of analysis, while exploring different service features and characteristics. Following this trend the literature related to the service dimension of DSI focuses on one or a few features, conceptualizes and classifies services along a number of service features, or discusses emerging variations of services.

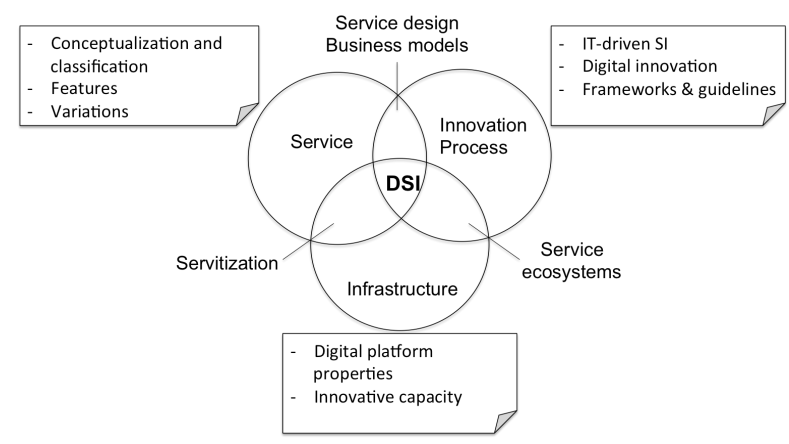

Figure 2: Digital service innovation

5.1.1. Service features Literature focused on one or a few features can be clustered into business, technology, or interaction. The business cluster includes features such as business objectives, funding and pricing. Business objectives refer to the service provider's motives for offering the digital service. These objectives could be strictly financial, but can also be related to competitiveness, cost reduction, optimization or customer loyalty [39]. BDA is regarded as an enabling technology to realize, inform and steer such objectives within various application domains [41].

The two features funding and pricing are mainly discussed in relation to the conception, viability and sustainability of a service. Traditionally, they represent crucial provider-driven features, having implications on business and revenue models. However, due to the emergence of pay as you go and dynamic pricing models, pricing is becoming a strong user-driven feature reflecting a cornerstone in the value proposition $[39,40]$. Dynamic pricing models are feasible due to software as a service (SaaS) offering and BDA [51,52].

The technology cluster encompasses the technological foundations upon which a service is designed, mediated or delivered. Choices of technology could be concerned with a component as specific as a database or a whole service platform [39]. The choice of underlying technology also influences the service delivery feature, albeit its user-oriented nature. Choosing to design a service on a specific technology (e.g. Android platform) has its implications on the prospect users (Android phone users) to which the service and associated content will be delivered [16]. Literature on BDA provides interesting examples of innovation along the technology cluster, where data, information, knowledge and their associated analytical capabilities are offered and delivered as services through cloud infrastructures [14][44-46].

The third cluster, interaction, can be illustrated through two representations. The first representation refers to the interaction between a user and a digital service through the service interface [39]. This type of interaction has long benefited from research on humancomputer interaction ( $\mathrm{HCI}$ ), and is now witnessing the emergence of research on intelligent and cognitive service systems. BDA is identified among the key technologies that enable such cognitive smart systems [11]. Visual analytics (VA) of big data could be regarded as a pillar to this type of interaction, since it combines principles from HCI, advanced analytics and visualization [48-50]. The second representation is seen through interaction among users in social and collaborative services. Increasingly, this type of interaction also links to the business objective since the interaction and the data it generates are becoming the assets for companies such as LinkedIn and Facebook. The big data generated on their platforms are used to offer their users a variety of BDA-based services [47].

The third type, malleability, represents the ability to respond or adapt to changing needs or changes in the service. A good service design allows service providers to be malleable in response to arising needs, and the resulting changes would impact user malleability [39].

5.1.2. Service conceptualization The divide between provider and user driven service features is a common one. Sawng et al. [40] differentiate between these two perspectives and assess their impact on the perceived usefulness and intention of reuse of a service. In a similar mode, Williams et al. [39] outline taxonomy to classify digital services along the provider and design objectives. Den Hertog's [18] model of service innovation is a different example of how services can be categorized. The model focuses on service novelty along four features: service concept, client interface, service delivery system, and technology. Innovation is not only realized when a new concept emerges, but can occur in relation to any of the four features (i.e. new context or through a new technology). While we found no evidence of BDA literature supporting efforts of service categorization, the potential persists for BDA to offer novel insights to service science [10][57]. 
5.1.3. Service variations Since Eaton et al.'s [86] definition accommodates services that are not entirely digitalized, our literature search yielded two service variations: product-service systems (PSS) and knowledge-intensive digital services (KIDS). PSS is the combination of product and service - also called servitization, often motivated by technological development [8]. This led to the emergence of cyberphysical systems and the innovation of digitally embedded services, especially in manufacturing industries [9][53]. Just like manufacturing was affected by automation, knowledge intensive industries are witnessing a major change with digitization and BDA [78]. Unlike KIDS, a few empirical cases of big data enabled servitization have been reported in the literature, from providing aircraft engines as services to remote maintenance services, enabled through sensing, adaptive learning and real-time data analysis [8][54].

Indeed, the service dimension covers different aspects that promote innovative digital services. While BDA contributes to the design and delivery of digital services, as well as creating new opportunities for service providers, the influence of BDA on user-driven features such as malleability and perceptions of innovativeness are yet to be explored. Using BDA to for data-driven classification of services is believed to bring in theoretical and practical knowledge in service research. Moreover, further understanding of how BDA enables innovation in cyber-physical systems and KIDS - as variations of digital services - is needed.

\subsection{The innovation process}

This stream is the most pragmatic in its approach, covering a range of issues affecting different stages of the innovation process, from practical guides to developing innovative digital services [63,64], emerging business models for data-driven and digital services [55,56][65], and participant contribution [66]. During the synthesis of the process-centric literature of DSI, few papers were found to study the mechanisms by which BDA contributes DSI process [41][79].

Yet, if we look at DSI and BDA as distinct fields with regards to this stream, we can still see two prevalent ways they can benefit one another. First, process-centric DSI is wealthy with knowledge on business models for innovation that could better inform the realization of value from data analytics and monetization of data $[55,56]$. Note that such studies describe business models that nurture service innovation, unlike service-specific business models mentioned in the previous section. Second, BDA enables the development of data science methods as emerging modes of scientific enquiry [57]. For example, BDA methods can be used to model service networks, support decision-making at various phases along the service innovation process and enhance an organization's environmental scanning and competitive intelligence $[19,20][23]$. To understand these two relationships better, we first take a closer look at the status quo and role of technology in DSI processes.

In relation to this stream of DSI literature, technology has primarily taken the role of operant resource [15]; an enabler to the whole service exchange and innovation processes. This role is consistent with SD logic in the sense that the key resources in exchange are presumed to be knowledge and skills, which are enabled by IT, to act upon other resources in order to create value [58]. However, more recently Lusch and Nambisan [59] highlighted the role of technology as both operant and operand resources. This implies that technology could be an enabler as well as an actor within the service ecosystems, making it difficult to separate between the two roles.

Departing from the theorization of technology in service innovation, scholars are mostly interested in identifying how service innovations are realized. Two distinct phases of IT-driven service innovation are identified: (1) service design, and (2) implementation $[60,61]$. During these two phases, the role of technology is highlighted both on the micro and macro levels. On the micro - service - level, IT is part of the service concept or definition and an integral part of a digital service [60]. Whereas on the macro - system level, the alignment of IT architecture and service infrastructure with the strategy is vital $[61,62]$.

Nevertheless, challenges emerge when putting such practices to the test. One challenge is the strain between the call for standardization and service innovation. Hanseth and Bygstad [67] suggest that the standardization strategy of flexible generification, a bottom up approach that works from work processes towards standardization of solutions, works best at easing this tension. However, innovating services is not always accomplished in a linear fashion, but rather in open collaborative (OC) networks.

There have been calls for research on how BDA can enable OC, by describing the complex network of contributors and how they function. Since teams in OC networks work on modules, it is important to conceptualize and visualize their enacted roles from a socio-technical multi-modal viewpoint. This gap continues to grow and creates an opportunity for BDA in modeling such networks and roles [20,23].

Two types of innovation processes include similar challenges: a) harvested innovation, where a service was deployed before, and b) discovered innovation [68]. The first challenge is the lack of a clear understanding of the collaborative processes by which innovations are harvested or discovered, especially in 
the presence of big data. Second, when the innovation network is already established, utilizing generated big data to support new services is minimal. Accordingly, the process of interpreting and enacting extracted knowledge to decisions remains vague and random.

Even though very few studies investigated the mechanisms of BDA-enabled innovation, analytical insights could potentially support DSI through modeling service networks, supporting decisionmaking, and enhancing environmental scanning capabilities. In addition, organizations investing in BDA could adopt emerging DSI business models to monetize and generate value.

\subsection{The infrastructure}

Digital infrastructures can be described as the pillar of DSI. In this context, DSI is described in terms of combining digital and physical components to enable the design and delivery of novel products or services [16][59]. Such digital and physical technologies are introduced within organizational contexts, which in turn affect human actors, socio-material practices [69], and even organizational identities [70]. Thus, this stream takes particular interest in the properties and innovation of the digital infrastructure, rather than the innovation process or a specific service.

The properties of digital infrastructures have been discussed in numerous papers from IS and other disciplines. Kallinikos et al. [71] have reviewed most of such properties, and argue that digital artifacts are editable, interactive, reprogrammable and distributable. These properties are generic and accommodate different subcategories of digital artifacts: platforms, infrastructures, and even digital products - including digital content. Since digital products and content can be regarded as variants of digital services, in this stream we focus on digital platforms.

Some authors attribute the digital platforms' innovative properties to their evolving architectures, from modular architectures with tight coupling between the device, network, service and content, to layered modular architecture of loosely coupled components [16]. Between those ends lies a continuum of re-programmability and self-reference of platforms, which promotes innovation but also raises issues of integrity and structural flexibility $[17,72]$.

Given the paradoxical tension between the integrity of the digital platforms and the structural flexibility that promotes innovation, boundary resources - such as APIs - were introduced to manage such tension $[9,17]$. Yet again, this structural flexibility of digital platforms invites distributed and uncoordinated actors to innovate on such platforms. Think of mobile application developers combining existing components and boundary resources in new ways to deliver a new digital service. DSI now features the generativity of digital platforms, a concept that emerged initially as a property of the Internet and the PC [73,74].

While digital platforms have been theorized in the above-mentioned ways, big data platforms are yet to be conceptualized in terms of properties and innovative mechanisms. In section 5.1 we illustrated how big data and Analytics-as-a-service (AaaS) reinforce each other, but it is still unclear how the underlying service platform would look like. On the conceptual side, some researchers propose BDA systems as collective intelligence systems [75]. Other scholars propose cloud-based AaaS architectures as service provisioning platforms [44,45]. On the other hand, Pääkkönen \& Pakkala [76] suggested reference architecture for big data systems behind major digital services such as Netflix and Facebook.

Alternately, in [14] a service-oriented decision support system is designed to accommodate big data and analytics in the cloud. Servitizing information is provisioned in three forms. When data is almost raw, very close to data collection, what is offered is known as Data-as-a-Service. Information-as-a-Service is then provisioned in later stages of data processing. Finally, agile analytics or AaaS is provisioned in a form that allows for agile decision-making based on knowledge discovered from big data [14].

Using BDA within DSI ecosystems comes with its own challenges. In social sciences, privacy concerns rattle the most as data on individuals is collected in great volumes and detail. Since our BDA definition covers social and ethical values, privacy preservation must form an essential pillar of big data activities within service ecosystems. To date, efforts done towards privacy preservation of service users have always been met with a compromise on the quality of studies in the fields of social sciences [11][13][32][77].

To sum up, digital infrastructures are theorized from various perspectives. Digital platforms as a type of infrastructure with properties such as layered modularity, structural flexibility and generativity are all discussed thoroughly in the literature, but do not take big data and its analytical capabilities into consideration. Understanding the role of digital technologies and BDA in service innovation, whether as an enabler or as a core artifact, helps us pinpoint specific research gaps that we discuss in details next.

\section{Discussion and research agenda}

In the service dimension, conceptualization, features and variations of digital services were discussed. Models and taxonomies of services [39,40] offer theoretical basis for classifying services; 
however, our scientific knowledge can be further developed by data-driven classification thereof. BDA was found to be a way to generate insights on users and markets, but rarely on services $[42,68]$. Conducting service segmentation could advance our understanding of services and service decision-making. Hence, the two research questions:.

- How can digital services be understood through BDA? How can digital services be dynamically clustered and profiled?

Service features shed light on important issues to consider while designing new digital services. For many of the features, it is quite clear how BDA informs the design of services [43]. Taking an example from the e-commerce domain, recommendation services are designed with the business objectives of cross-selling and customer satisfaction, and are enabled by analytical techniques such as association rule mining [42]. However, BDA is not utilized to support other features such as malleability and perception of innovativeness. A few scholars (e.g. [79]) studied the relationship between analytics, innovativeness and competitive advantage, albeit from service providers' viewpoint. More studies are needed to report if and how BDA insights affect malleability - of both user and provider. Accordingly, the following research question helps to further explore these relationships.

- How does BDA affect malleability of services?

As we move along the technological frontiers from scarcity to abundance - of services and data - we become in dire need to make sense and create value from big data [11]. Analytical models are often complicated and distant from the decisions they are supposed to support. If the extracted knowledge is difficult to comprehend by decision-makers or consumed ineffectively through operational actions, little to no value is created [41]. While research on interaction and VA tackles this problem, it is still limited compared to non-visual exploration and analysis options of BDA. One potential area of research that could allow for more intuitive service decisions is that of visual analytics.

- How can BDA service models be simplified to be consumed by non-technical users? What are the visualization options to enhance the value of extracted knowledge?

Even though the characteristics and features provide a good understanding of services, there is a knowledge gap on those variations of digital services such as cyber-physical systems and KIDS. Especially with regards to BDA, it is unclear how BDA enables the design of services with associated products or knowledge-intensive environments [19][54][78].

- How does BDA enable cyber-physical systems (or PSS)?
- How does BDA enable the design and delivery of KIDS?

As we described earlier, the role of BDA in the innovation process is not clearly evident in the literature. Yet, we argue for two ways the domains of DSI and BDA can benefit one another, along the process of innovation. The first way is for DSI to make use of BDA as a method for scientific enquiry [57]. When services are provisioned through a collaborative network, the innovation process becomes more challenging, both to understand and to conduct. This calls for research to understand the dynamics of such networks, the enacted roles and processes [20].

- How can BDA enable understanding DSI value networks? How can BDA be used to capture enacted roles and processes by which value networks operate?

The second way is to study business models of DSI to monetize over BDA efforts through value added services [55,56][65]. Adopting such business models is not a straightforward task, though, since other factors come into play. LaValle et al. [41] argue that insights that are closely linked with business strategy, easy to use and embedded in the service workflow are crucial to value creation from BDA. However, the dynamics of this path could be different from one service provider(s) to another, and the literature lacks this knowledge. Thus, we suggest exploring the dynamics of the innovation process of BDA-enabled services through business models, while considering the values of different stakeholders.

- How do BDA insights enable value creation and value capture towards service innovation? How do different business models influence this process?

Literature on DSI infrastructure points to an increasing interest in their nature, mechanisms and innovative capacity. They have been theorized in light of their various properties, but the big data generated on these platforms is often ignored. As big data continues to grow on digital platforms and become situated in surrounding ecosystems, we identify four opportunities for DSI enabled by BDA, in relation to infrastructure. For instance, it is argued that the higher the homogenization of data combined from heterogeneous sources, the higher the innovative capacity is [16]. Since variety is an essential defining property of big data, a research opportunity arises, in which we would understand how the advancements of big data could contribute to the homogenization, or seamlessly accommodate the heterogeneity, of data and in turn impact DSI.

- In what ways can big data enable a platform's layered modular architecture while imposing less constraints of data homogenization? 
While the generativity of digital platforms has been studied thoroughly [17][74], that of big data has been rarely discussed [83]. In addition, the relationship between platform generativity and big data remains untapped in the context of service innovation. The following questions act as guiding research questions:

- What is the relationship between digital platforms' generativity and big data generation? How can big data enable sustainable generativity of digital platforms?

Privacy remains a burning issue in the age of big data due to monetization and sharing of data. Social actors, including users and citizens, are increasingly concerned about the amount of information shared about them and the compromises they need to make to use a particular service [32,77]. Thus, this research area needs to be tackled from legal, technical and social perspectives. We suggest the following question:

- How can BDA techniques and methods be improved to ensure privacy preservation in digital service platforms?

The previous examples, while not comprehensive, provide an overview on the discourse of DSI. By deconstructing this domain, we found various research gaps that may further develop our understanding of BDA-enabled DSI, where these research questions act as starting points to a way forward.

\section{Concluding remarks}

It has been experimental that revolution in science has quite often been preceded by revolution in measurement, whereby scientific discovery is accustomed to make projections grounded on accepted theories. Conversely, Big Data Analytics (BDA) is currently adept at delivering trustworthy projections based on executing a data science process while seemingly abstaining from being theoretically informed about the subject matter. The contribution of this research lies in formally intertwining BDA and DSI, a phenomenon observed in practice and is of increasing interest to the IS community [78]. Towards this end, we conducted a literature review to deconstruct DSI and its constituent dimensions, and how BDA contributes to the development thereof.

While it is most common for BDA to make projections pertaining to the three identified DSI dimensions, it is also shown that BDA research benefits from digitalization and servitization; thus the relationship is bidirectional. This marriage between the two domains is setout to place foundations for future research that would enable faster realizations of innovative service design and delivery, which would create value for businesses and the society in dataintensive environments.

\section{References}

[1] H. Snyder, L. Witell, A. Gustafsson, P. Fombelle, and P. Kristensson. "Identifying categories of service innovation: A review and synthesis of the literature." Journal of Business Research, vol. 69(79), 2016, pp. 2401-2408.

[2] A. Kaplan \& M. Haenlein, "Users of the world, unite! the challenges and opportunities of social media." Business Horizons, 53(1), 2010, pp. 59-68.

[3] J. Gubbi, R. Buyya, S. Marusic \& M. Palaniswami, "Internet of things (IoT): A vision, architectural elements, and future directions." Future Generation Computer Systems, vol. 29(7), 2013, pp. 1645-1660.

[4] B. Bergvall-Kåreborn \& D. Howcroft, "Amazon Mechanical Turk and the commodification of labour." New Technology, Work and Employment, vol. 29(3), 2014, pp. 213-223.

[5] I. Blohm, J.M. Leimeister \& H. Krcmar, "Crowdsourcing: How to benefit from (too) many great ideas." MIS Quarterly Executive, vol. 12(4), 2013, pp. 199-211.

[6] A. Ostrom, M. Bitner, S. Brown, K. Burkhard, M. Goul, V. Smith-Daniels, \& E. Rabinovich, "Moving forward and making a difference: Research priorities for the science of service." Journal of Service Research, vol. 13(1), 2010, pp. 4-36.

[7] C. Van Halen, C. Vezzoli, \& R. Wimmer "Methodology for Product Service System Innovation." Uitgeverij Van Gorcum, 2005.

[8] A. Neely, "Exploring the financial consequences of the servitization of manufacturing" Operations Management Research, vol. 1(2), 2008, pp. 103-118.

[9] M. Barrett, E. Davidson, J. Prabhu \& S. Vargo "Service Innovation in the Digital Age: Key Contributions and Future Directions.” MIS Quarterly, vol. 39(1), 2015, pp. 135-154.

[10] C. Breidbach \& P. Maglio "Does big data provide big opportunities for service research? Service Excellence in Management, Karlstad, 2013, pp. 187-189.

[11] H. Demirkan, C. Bess, J. Spohrer, A. Rayes, D. Allen \& Y. Moghaddam "Innovations with smart service systems: Analytics, big data, cognitive assistance, and the Internet of everything" Communications of the AIS, vol. 37(1), 2015, no. 35.

[12] T. Davenport "Big data at work: Dispelling the myths, uncovering the opportunities" Harvard Business Review Press, 2014

[13] J. Shim, A. French, C. Guo \& J. Jablonski "Big data and analytics: Issues, solutions, and ROI" Communications of the AIS, vol. 37(1), 2015, no. 39.

[14] H. Demirkan \& D. Delen "Leveraging the capabilities of service-oriented decision support systems: Putting analytics and big data in cloud." Decision Support Systems, vol. 55(1), 2013, pp. 412-421.

[15] M. Akaka \& S. Vargo "Technology as an operant resource in service (eco) systems." Information Systems and E-Business Management, vol. 12(3), 2014, pp. 367-384.

[16] Y. Yoo, O. Henfridsson \& K. Lyytinen "Research commentary-the new organizing logic of digital innovation: An agenda for information systems research." Information Systems Research, vol. 21(4), 2010, pp. 724-735. 
[17] B. Eaton, S. Elaluf-Calderwood, C. Sørensen \& Y. Yoo "Distributed tuning of boundary resources: The case of apple's iOS service system" MIS Quarterly, vol. 39(1), 2015, pp. 217-243.

[18] P. Den Hertog "Knowledge-intensive business services as co-producers of innovation" International Journal of Innovation Management, vol. 4(4), 2000, pp. 491-528.

[19] Y. Chu \& S. Lin "Network ontology and dynamics analysis for collaborative innovation in digital services." Proceedings of PICMET, 2011, pp. 1-4.

[20] S. Brunswicker, E. Bertino, \& S. Matei "Big data for open digital Innovation-A research roadmap" Big Data Research, vol. 2(2), 2015, pp. 53-58.

[21] S. Vargo, P. Maglio, \& M. Akaka "On value and value co-creation: A service systems and service logic perspective" European Management Journal, vol. 26(3), 2008, pp. 145152.

[22] B. Baesens, R. Bapna, J. Marsden, J. Vanthienen \& J. Zhao "Transformational issues of big data and analytics in networked business" MIS Quarterly, vol. 38(2), 2014, pp. 629-631.

[23] R. Agarwal \& V. Dhar "Big data, data science, and analytics: The opportunity and challenge for IS research" Information Systems Research, vol. 25(3), 2014, pp. 443-448. [24] T. Davenport \& D. Patil "Data scientist" Harvard Business Review, 90, 2012, pp. 70-76.

[25] A. McAfee \& E. Brynjolfsson "Big data: The management revolution" Harvard Business Review, 90, 2012, pp. 60-68.

[26] W. Fan \& A. Bifet "Mining big data: Current status, and forecast to the future." ACM SIGKDD Explorations Newsletter, vol. 14(2), 2013, pp. 1-5.

[27] Y. Yoo "It is not about size: A further thought on big data" Journal of Information Technology, vol. 30(1), 2015, pp. 63-65.

[28] A. Gandomi \& M. Haider "Beyond the hype: Big data concepts, methods, and analytics" International Journal of Information Management, vol. 35(2), 2015, pp. 137-144.

[29] H. Jagadish "Big data and science: Myths and reality" Big Data Research, vol. 2(2), 2015, pp. 49-52.

[30] J. Anuradha "A brief introduction on big data 5Vs characteristics and hadoop technology" Procedia Computer Science, vol. 48, 2015, pp. 319-324.

[31] X. Wu, X. Zhu, G. Wu, \& W. Ding "Data mining with big data" IEEE Transactions on Knowledge and Data Engineering, vol. 26(1), 2014, pp. 97-107.

[32] M. Jensen "Challenges of privacy protection in big data analytics" Proceedings of IEEE International Congress on Big Data, 2013, pp. 235-238.

[33] D. Boyd \& K. Crawford "Critical questions for big data: Provocations for a cultural, technological, and scholarly phenomenon" Information, Communication \& Society, vol. 15(5), 2012, pp. 662-679.

[34] J. Webster \& R. Watson "Analyzing the past to prepare for the future: Writing a literature review" MIS Quarterly, vol. 26(2), 2002, pp. xiii-xxiii.

[35] Y. Levy \& T. Ellis "A systems approach to conduct an effective literature review in support of information systems research" Informing Science Journal, vol. 9(1), 2006, pp. 181-212.
[36] J. Vom Brocke, A. Simons, B. Niehaves, K. Riemer, R. Plattfaut \& A. Cleven "Reconstructing the giant: On the importance of rigour in documenting the literature search process" ECIS Proceedings, 2009, pp. 2206-2217.

[37] H. Hsieh \& S. Shannon "Three approaches to qualitative content analysis" Qualitative Health Research, vol. 15(9), 2005, pp. 1277-1288.

[38] J. Sandberg \& M. Alvesson "Ways of constructing research questions: Gap-spotting or problematization?" Organization, vol. 18(1), 2011, pp. 23-44.

[39] K. Williams, S. Chatterjee \& M. Rossi "Design of emerging digital services: A taxonomy" European Journal of Information Systems, vol.17(5), 2008, pp. 505-517.

[40] Y. Sawng, J. Lee \& K. Motohashi "Digital convergence service from the viewpoint of provider and user factors using technology acceptance and diffusion model" Cluster Computing, vol. 18, 2015, pp. 293-308.

[41] S. LaValle, E. Lesser, R. Shockley, M. Hopkins \& N. Kruschwitz "Big data, analytics and the path from insights to value" MIT Sloan Management Review, vol.52(2), 2013, 21.

[42] H. Chen, R. Chiang, \& V. Storey "Business intelligence and analytics: From big data to big impact. MIS Quarterly, vol. 36(4), 2012, pp. 1165-1188.

[43] L. Caesarius \& N. Johansson "Developing innovative services based on big data: The case of Go:SMART" Service Excellence in Management, Karlstad, 2013, pp. 175-184.

[44] Z. Khan, A. Anjum, K. Soomro \& T. Muhammad "Towards cloud based big data analytics for smart future cities" Journal of Cloud Computing: Advances, Systems and Applications, vol. 4(2), 2015, pp. 1-11.

[45] F. Zulkernine, P. Martin, Y. Zou, M. Bauer, F. GwadrySridhar \& A. Aboulnaga "Towards cloud-based analytics-asa-service (CLAaaS) for big data analytics in the cloud." Big Data Congress, 2013, pp. 62-69.

[46] A. Depeige \& D. Doyencourt "Actionable knowledge as A service (AKAAS): Leveraging big data analytics in cloud computing environments" Journal of Big Data, vol. 2(1), 2015, pp. 1-16.

[47] S. Ahuja \& B. Moore "State of big data analysis in the cloud" Network and Communication Technologies, vol. 2(1), 2013, pp. 62-68.

[48] F. Fischer, J. Fuchs, F. Mansmann \& D. Keim "BANKSAFE: Visual analytics for big data in large-scale computer networks" Information Visualization, vol. 14(1), 2015, pp. 51-61.

[49] C. Vaitsis, G. Nilsson \& N. Zary "Big data in medical informatics: Improving education through visual analytics" Studies in Health Technology and Informatics, vol. 205, 2014, pp. 1163-1167.

[50] L. Zhang, A. Stoffel, M. Behrisch, S. Mittelstadt, T. Schreck, R. Pompl, \& D. Keim "Visual analytics for the big data era: A comparative review of state-of-the-art commercial systems" IEEE Conference On Visual Analytics Science and Technology, 2012, pp. 173-182.

[51] G. Phillips-Wren, L. Iyer, U. Kulkarni \& T. Ariyachandra "Business analytics in the context of big data: A roadmap for research" Communications of the AIS, vol. 37(1), 2015, no. 23.

[52] D. Wu, D. Rosen, L. Wang \& D. Schaefer "Cloud-based design and manufacturing: A new paradigm in digital 
manufacturing and design innovation" Computer-Aided Design, vol. 59, 2015, pp. 1-14.

[53] A. Neely, O. Benedettini \& I. Visnjic "The servitization of manufacturing: Further evidence" European Operations Management Association Conference, 2011, no. 1.

[54] J. Lee, H. Kao \& S. Yang "Service innovation and smart analytics for industry 4.0 and big data environment" Procedia CIRP, vol. 16, 2014, pp. 3-8.

[55] A. Baird \& T. Raghu "Associating consumer perceived value with business models for digital services" European Journal of Information Systems, vol. 24(1), 2015, pp. 4-22.

[56] J. Bram, B. Warwick-Clark, E. Obeysekare \& K. Mehta "Utilization and monetization of healthcare data in developing countries" Big Data, vol. 3(2), 2015, pp. 59-66.

[57] O. Müller, I. Junglas, J. vom Brocke \& S. Debortoli "Utilizing big data analytics for information systems research: Challenges, promises and guidelines" European Journal of Information Systems, 2016, pp. 1-14

[58] S. Vargo \& R. Lusch "It's all B2B and beyond: Toward a systems perspective of the market" Industrial Marketing Management, vol. 40(2), 2011, pp. 181-187.

[59] R. Lusch \& S. Nambisan "Service innovation: A service-dominant logic perspective" MIS Quarterly, vol. 39(1), 2015, pp. 155-175.

[60] C. Dominguez-Péry, B. Ageron \& G. Neubert "A service science framework to enhance value creation in service innovation projects: a RFID case study" International Journal of Production Economics, vol. 141(2), 2013, 440451.

[61] N. Ramasubbu, J. Woodard \& S. Mithas "Orchestrating service innovation using design moves: The dynamics of fit between service and enterprise IT architectures" International Conference on Information Systems, 2014, 35.

[62] H. Ryu, J. Lee, \& B. Choi, "Alignment between service innovation strategy and business strategy and its effect on firm performance: An empirical investigation" IEEE Transactions on Engineering Management, vol. 62(1), 2014, pp. 100-113.

[63] M. Bitner, A. Ostrom, \& F. Morgan "Service blueprinting: a practical technique for service innovation" California Management Review, vol. 50(3), 2008, pp. 66-94.

[64] D. Nylén, and J. Holmström. "Digital innovation strategy: A framework for diagnosing and improving digital product and service innovation." Business Horizons, vol. 58(1), 2015, pp. 57-67.

[65] K. Sandkuhl, \& J. Stirna "Capability-as-a-service: Investigating the innovation potential from a business model perspective." Advanced Information Systems Engineering Workshops, 2015, pp. 137-148.

[66] I. Kuzmickaja, X. Wang, D. Graziotin, G. Dodero \& P. Abrahamsson "In need of creative mobile service ideas? Forget adults and ask young children" SAGE Open, vol. 5(3), pp. 1-13.

[67] O. Hanseth \& B. Bygstad "Flexible generification: ICT standardization strategies and service innovation in health care." European Journal of Information Systems, 2015, pp. 119.

[68] A. Ghose, E. Morrison \& Y. Gou "A novel use of big data analytics for service innovation harvesting." International Conference on Service Science and Innovation, 2013, pp. 208-214.
[69] G. Kuk \& M. Janssen "Assembling infrastructures and business models for service design and innovation." Information Systems Journal, vol. 23(5), 2013, pp. 445-469.

[70] R. Lindgren, O. Eriksson \& K. Lyytinen "Managing identity tensions during mobile ecosystem evolution" Journal of Information Technology, vol. 30(3), 2015, pp. 229-244.

[71] J. Kallinikos, A. Aaltonen \& A. Marton "The ambivalent ontology of digital artifacts" MIS Quarterly, vol. 37(2), 2013, pp. 357-370.

[72] W. Orlikowski \& S. Scott "The algorithm and the crowd: Considering the materiality of service innovation" MIS Quarterly, vol. 39(1), 2015, pp. 201-216.

[73] J. Zittrain "The generative Internet" Harvard Law Review, 2006, pp. 1974-2040.

[74] O. Henfridsson \& B. Bygstad "The generative mechanisms of digital infrastructure evolution" $M I S$ Quarterly, vol. 37(3), 2013, pp. 907-931.

[75] K. Chen, X. Li \& H. Wang "On the model design of integrated intelligent big data analytics systems." Industrial Management \& Data Systems, vol. 115(9), 2015, pp. 16661682.

[76] P. Pääkkönen \& D. Pakkala "Reference architecture and classification of technologies, products and services for big data systems" Big Data Research, vol. 2(4), 2015, pp. 166186.

[77] J. Daries, J. Reich, J. Waldo, E. Young, J. Whittinghill, A. Ho \& I. Chuang "Privacy, anonymity, and big data in the social sciences" Communications of the ACM, vol. 57(9), 2014, pp. 56-63.

[78] C. Loebbecke \& A. Picot "Reflections on societal and business model transformation arising from digitization and big data analytics: A research agenda" The Journal of Strategic Information Systems, vol. 24(3), 2015, pp. 149-157. [79] Y. Duan \& G. Cao. "Understanding the Impact of Business Analytics on Innovation." European Conference of Information Systems, 2015, no. 40.

[80] B. Tether "Do services innovate (differently)? Insights from the European innobarometer survey." Industry \& Innovation, vol. 12(2), 2005, pp. 153-184

[81] A. Gawer and M. A. Cusumano "Platform leadership: How Intel, Microsoft, and Cisco drive industry innovation." Harvard Business School Press, 2002.

[82] A. Gawer. "Platforms, markets and innovation." Edward Elgar Publishing, 2011.

[83] H. Ekbia, M. Mattioli, I. Kouper, G. Arave, A. Ghazinejad, T. Bowman, V. Suri, A. Tsou, S. Weingart, and C. Sugimoto. "Big data, bigger dilemmas: A critical review." Journal of the Association for Information Science and Technology, vol. 66(8), 2015, pp. 1523-1545.

[84] C. Baldwin \& C. Woodard "The Architecture of Platforms: A Unified View" Harvard Business School Working Paper Series, 2008, pp. 9-34.

[85] J. Bosch. "From software product lines to software ecosystems." Proceedings of the International Software Product Line Conference, 2009, pp. 111-119.

[86] B. Eaton, S. Elaluf-Calderwood, C. Sørensen, \& Y. Yoo, "Dynamic structures of control and generativity in digital ecosystem service innovation: The cases of the Apple and Google mobile app stores" London School of Economics and Political Science, 2011. 